\title{
TeSTING OF A WOOden High-WALl GiRder LoAded over a Steel Plate on the ToP
}

\author{
Stanko Colak \& Damir Varevac
}
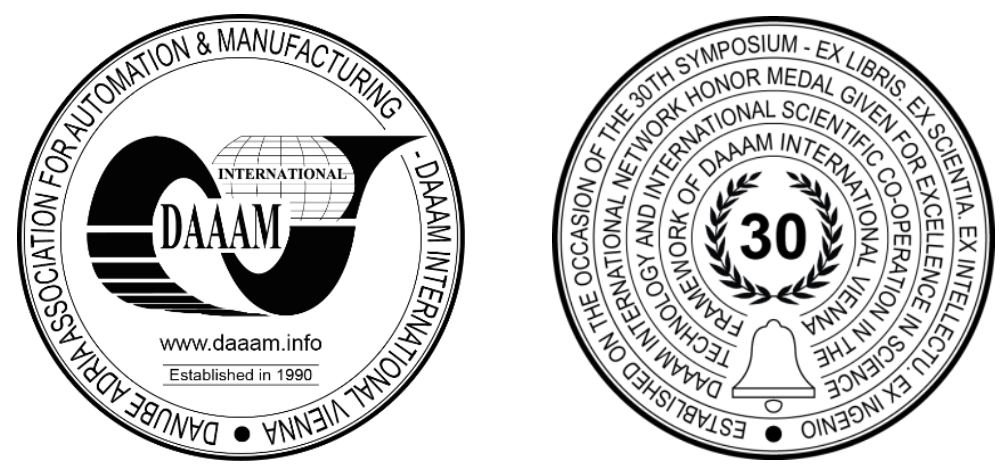

This Publication has to be referred as: Colak, S[tanko] \& Varevac, D[amir] (2021). Testing of a Wooden High-wall Girder Loaded over a Steel Plate on the Top, Proceedings of the 32nd DAAAM International Symposium, pp.0369-0376, B. Katalinic (Ed.), Published by DAAAM International, ISBN 978-3-902734-33-4, ISSN 1726-9679, Vienna, Austria DOI: $10.2507 / 32$ nd.daaam.proceedings.054

\begin{abstract}
In this paper, a test of wooden high-wall girders $5.0 \mathrm{~m}$ high, $0.18 \mathrm{~m}$ thick and of different widths compressed by a steel plate made of structural steel $20 \mathrm{~cm}$ wide and $2 \mathrm{~cm}$ thick was performed in the program Ansys. We have a total of 12 cases of loading the high-rise girder over the steel plate. The results of 3 high-wall girders were compared, the first $1.5 \mathrm{~m}$ wide, the second $1.15 \mathrm{~m}$ and the third $0.8 \mathrm{~m}$ loaded over a steel plate first with a force of $250 \mathrm{kN}$ then with a force of 500 $\mathrm{kN}$, with and without friction. The results show that the friction between the steel plate and the wooden high-wall girder has a small effect on the increase of the longitudinal stress of the high-wall girder. Also the width of the high-wall girder affects the normal stress in the length direction.
\end{abstract}

Keywords: wooden high-wall girder; steel plate; normal stress; Ansys.

\section{Introduction}

The task was to examine the normal stress of wooden high-wall girders in the direction of the length of the high-wall girders when they are loaded over the steel plate. The aim and purpose of the test is to describe the test results of highwall girders loaded over a steel plate and to compare the case where there is friction at the contact between the steel plate and the high-wall girder with the case when there is no friction at the contact between the high-wall girder and the plate. The problem to be solved by this work is to find out the place on the high-wall girder where the highest stress occurs and whether there are too many differences between the contacts between the high-wall girder and the plate without friction and when there is a friction coefficient of 0.4 .

The stress calculation of high-wall girders was performed in the program Ansys [1]. Further tests in this area will be the loading of wooden high-wall girders via a steel plate connected to the high-wall girder by means of screws. After the introduction, the dimensions and mechanical properties of the wooden high-wall girder are described in the second part. The procedure for testing high-wall girder samples in Ansys was then described. The test results are presented and described. A conclusion was written at the end of the paper. 


\section{Dimensions and mechanical properties of wooden high-wall girder}

Figure 1 shows a model of a wooden high-wall girder with a steel plate on top from the program Ansys [1]. The highwall girder is $5.0 \mathrm{~m}$ high, $0.18 \mathrm{~m}$ thick and of various widths loaded over a steel plate made of structural steel $20 \mathrm{~cm}$ wide and $2 \mathrm{~cm}$ thick. We have three different high-wall girders according to the width dimensions: high-wall girders with a width of $1,50,1,15$ and $0,8 \mathrm{~m}$.

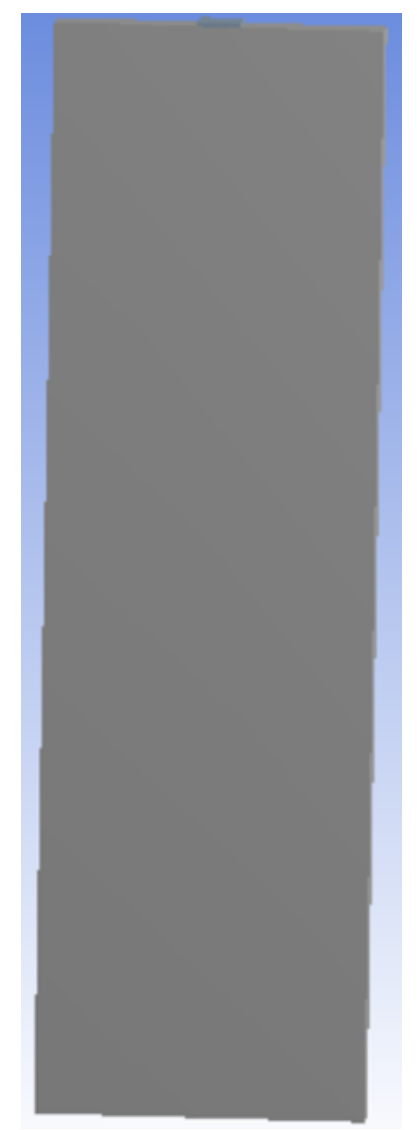

Fig. 1. High-wall girder from program Ansys [1]

Figure 2 shows the mechanical properties of a wooden high-wall girder. The density of the wood from which the highwall girder is made is $410 \mathrm{~kg} / \mathrm{m} 2$, and the Poisson's ratio is 0.3 . The Young's modulus of elasticity of wood in the fiber direction is $12600 \mathrm{MPa}$, and the Young's modulus of elasticity of wood perpendicular to the fiber direction is $420 \mathrm{MPa}$. The shear modulus in all three directions is equal to $420 \mathrm{MPa}$ [2].

\begin{tabular}{|c|c|c|c|c|c|c|}
\hline 1 & Property & Value & Unit & & ( & [p] \\
\hline 2 & 7 Material Field Variables & 围 Table & & & & \\
\hline 3 & 7 Density & 410 & $\mathrm{~kg} \mathrm{~m} \mathrm{~m}^{\wedge}-3$ & 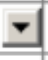 & $\square$ & $\square$ \\
\hline 4 & $\square \bigoplus$ Orthotropic Elasticity & & & & $\square$ & \\
\hline 5 & Young's Modulus X direction & 12600 & $\mathrm{MPa}$ & $\nabla$ & & $\square$ \\
\hline 6 & Young's Modulus Y direction & 420 & $\mathrm{MPa}$ & $\nabla$ & & $\square$ \\
\hline 7 & Young's Modulus Z direction & 420 & $\mathrm{MPa}$ & $\nabla$ & & $\square$ \\
\hline 8 & Poisson's Ratio XY & 0,3 & & & & $\square$ \\
\hline 9 & Poisson's Ratio YZ & 0,3 & & & & 回 \\
\hline 10 & Poisson's Ratio XZ & 0,3 & & & & 回 \\
\hline 11 & Shear Modulus XY & 420 & $\mathrm{MPa}$ & $\nabla$ & & $\square$ \\
\hline 12 & Shear Modulus YZ & 420 & $\mathrm{MPa}$ & $\nabla$ & & 回 \\
\hline 13 & Shear Modulus XZ & 420 & $\mathrm{MPa}$ & $\nabla$ & & $\square$ \\
\hline
\end{tabular}

Fig. 2. Mechanical properties of the wood from which the high-wall girder is made [1] 


\section{Test procedure and results}

The test procedure was performed in such a way that the high-wall girder support was clamped on the underside and compressed on the upper side via a $2 \mathrm{~cm}$ thick steel plate. We have a total of 12 samples of high-wall girder:

1. high-wall girder $5 \mathrm{~m}$ high and $1,5 \mathrm{~m}$ long loaded over the steel plate with the force of $250 \mathrm{kN}$ without friction at the contact between the high-wall girder and the steel plate,

2. high-wall girder $5 \mathrm{~m}$ high and $1,5 \mathrm{~m}$ long loaded over the steel plate with the force of $500 \mathrm{kN}$ without friction at the contact between the high-wall girder and the steel plate,

3. high-wall girder $5 \mathrm{~m}$ high and $1,5 \mathrm{~m}$ long loaded over the steel plate with the force of $250 \mathrm{kN}$ with friction at the contact between the high-wall girder and the steel plate (coefficient of friction on the contact surface is equal 0,4),

4. high-wall girder $5 \mathrm{~m}$ high and $1,5 \mathrm{~m}$ long loaded over the steel plate with the force of $500 \mathrm{kN}$ with friction at the contact between the high-wall girder and the steel plate (coefficient of friction on the contact surface is equal 0,4),

5. high-wall girder $5 \mathrm{~m}$ high and 1,15 $\mathrm{m}$ long loaded over the steel plate with the force of $250 \mathrm{kN}$ without friction at the contact between the high-wall girder and the steel plate,

6. high-wall girder $5 \mathrm{~m}$ high and 1,15 $\mathrm{m}$ long loaded over the steel plate with the force of $500 \mathrm{kN}$ without friction at the contact between the high-wall girder and the steel plate,

7. high-wall girder $5 \mathrm{~m}$ high and $1,15 \mathrm{~m}$ long loaded over the steel plate with the force of $250 \mathrm{kN}$ with friction at the contact between the high-wall girder and the steel plate (coefficient of friction on the contact surface is equal 0,4 ),

8. high-wall girder $5 \mathrm{~m}$ high and $1,15 \mathrm{~m}$ long loaded over the steel plate with the force of $500 \mathrm{kN}$ with friction at the contact between the high-wall girder and the steel plate (coefficient of friction on the contact surface is equal 0,4),

9. high-wall girder $5 \mathrm{~m}$ high and $0,8 \mathrm{~m}$ long loaded over the steel plate with the force of $250 \mathrm{kN}$ without friction at the contact between the high-wall girder and the steel plate,

10. high-wall girder $5 \mathrm{~m}$ high and $0,8 \mathrm{~m}$ long loaded over the steel plate with the force of $500 \mathrm{kN}$ without friction at the contact between the high-wall girder and the steel plate,

11. high-wall girder $5 \mathrm{~m}$ high and $0,8 \mathrm{~m}$ long loaded over the steel plate with the force of $250 \mathrm{kN}$ with friction at the contact between the high-wall girder and the steel plate (coefficient of friction on the contact surface is equal 0,4),

12. high-wall girder $5 \mathrm{~m}$ high and 1,5 m long loaded over the steel plate with the force of $500 \mathrm{kN}$ with friction at the contact between the high-wall girder and the steel plate (coefficient of friction on the contact surface is equal 0,4 ).

The calculation was performed in the program Ansys and the results of the normal stress of the high-rise girder in the direction of its width are presented.

\subsection{High-wall girder 1,5 $\mathrm{m}$ wide and loaded with the force of $250 \mathrm{kN}$ without friction}

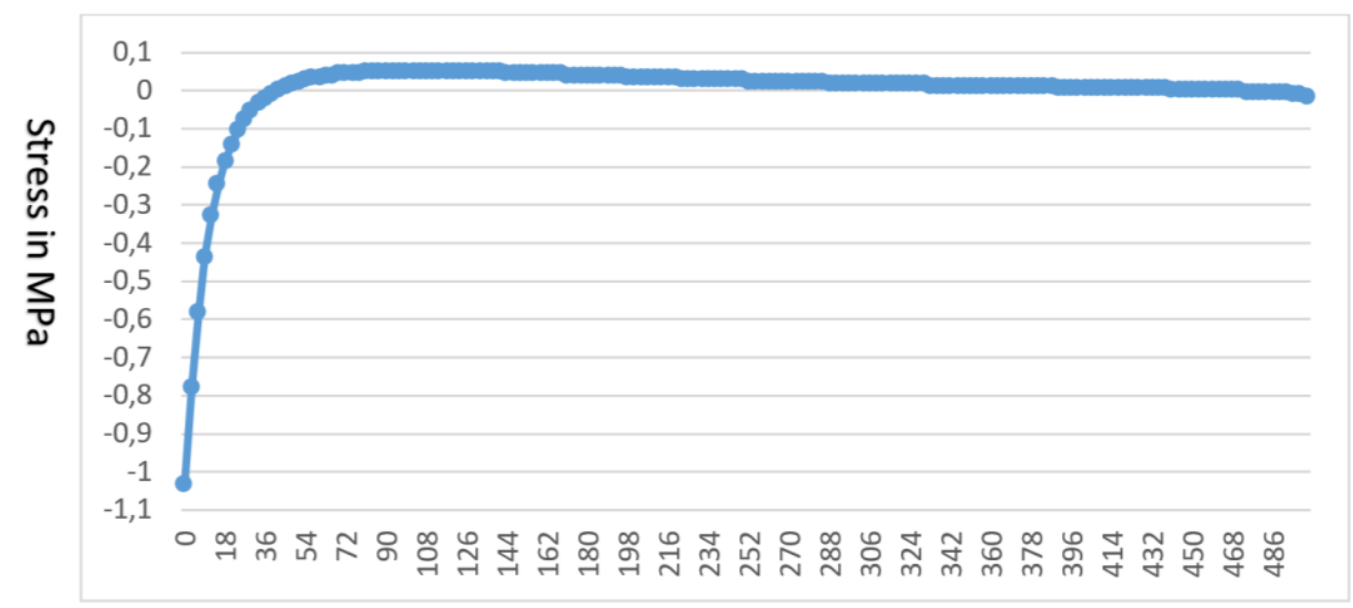

Vertically distance from the top

Fig. 3. Stress along the height of the high-wall girder

The maximum normal stress is at a distance of $105 \mathrm{~cm}$ from the top of the high-wall girder and is 0,050912 MPa. 
3.2. High-wall girder 1,5 $\mathrm{m}$ wide and loaded with the force of $500 \mathrm{kN}$ without friction

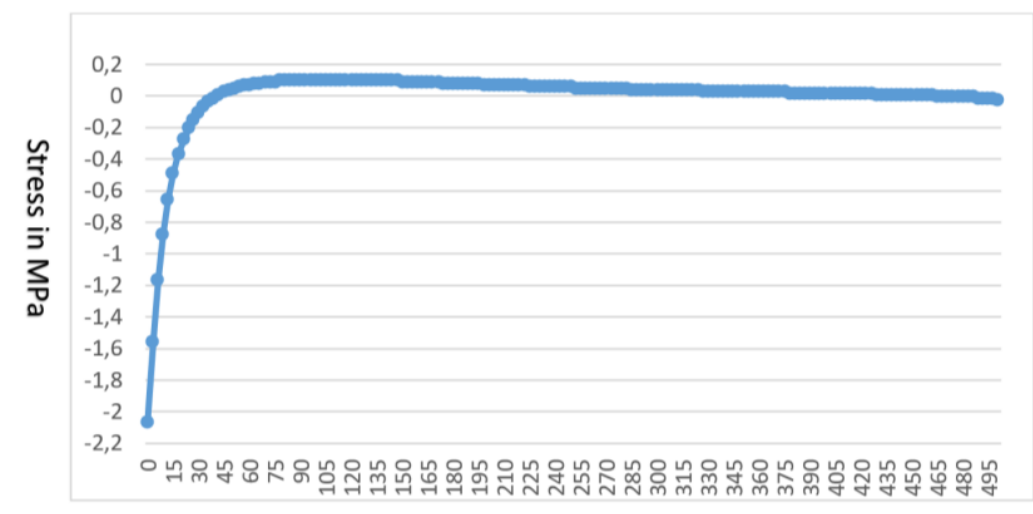

Vertically distance from the top

Fig. 4. Stress along the height of the high-wall girder

The maximum normal stress is at a distance of $105 \mathrm{~cm}$ from the top of the high-wall girder and is $0,10182 \mathrm{MPa}$.

3.3. High-wall girder 1,5 $\mathrm{m}$ wide and loaded with the force of $250 \mathrm{kN}$ with friction

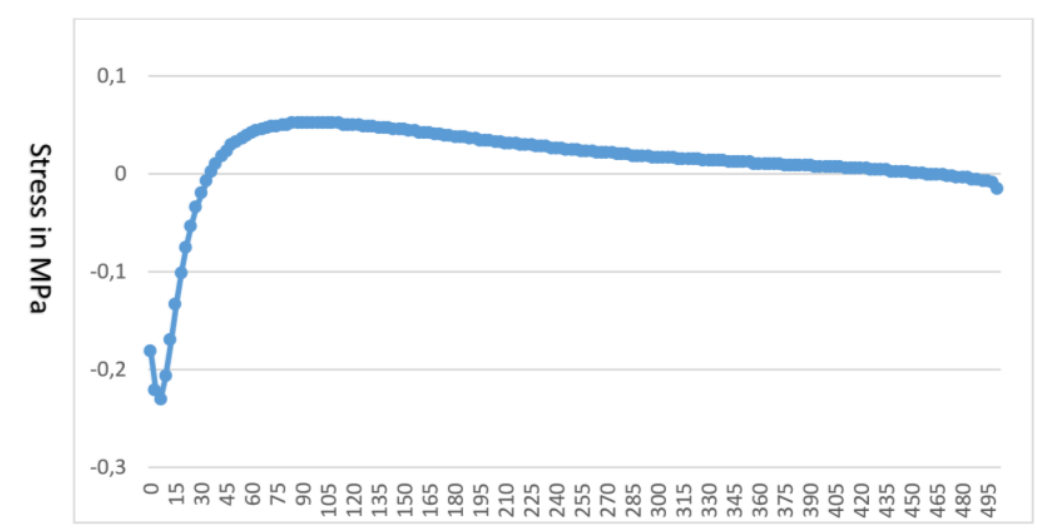

Vertically distance from the top

Fig. 5. Stress along the height of the high-wall girder

The maximum normal stress is at a distance of $96 \mathrm{~cm}$ from the top of the high-wall girder and is 0,051692 MPa.

3.4. High-wall girder 1,5 $\mathrm{m}$ wide and loaded with the force of $500 \mathrm{kN}$ with friction

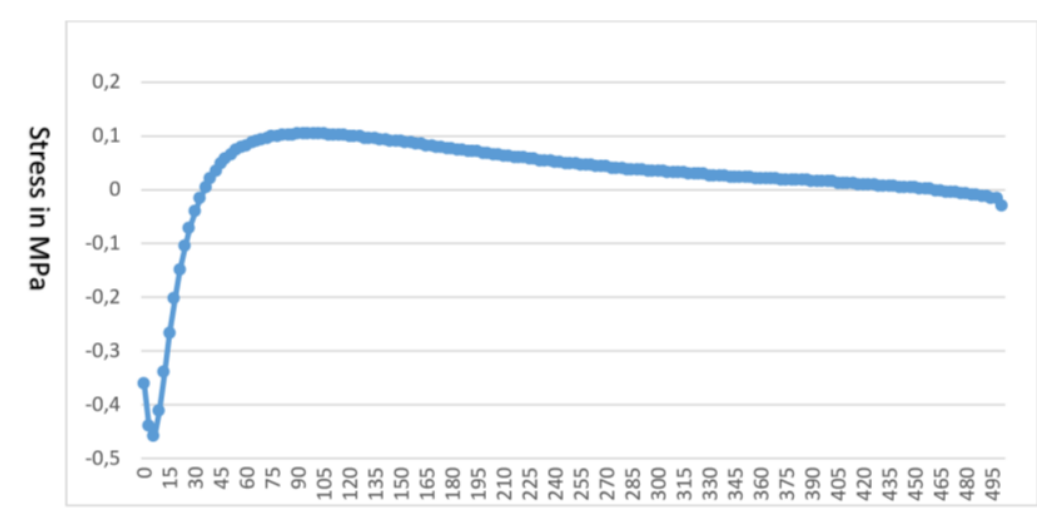

\section{Vertically distance from the top}

Fig. 6. Stress along the height of the high-wall girder

The maximum normal stress is at a distance of $96 \mathrm{~cm}$ from the top of the high-wall girder and is $0,10338 \mathrm{MPa}$. 
3.5. High-wall girder 1,15 $\mathrm{m}$ wide and loaded with the force of $250 \mathrm{kN}$ without friction

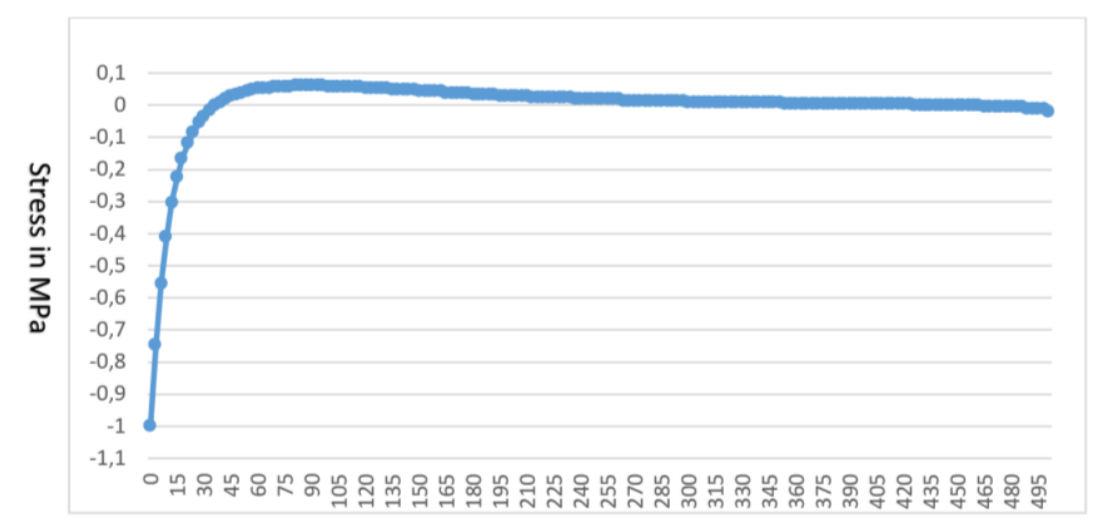

Vertically distance from the top

Fig. 7. Stress along the height of the high-wall girder

The maximum normal stress is at a distance of $87 \mathrm{~cm}$ from the top of the high-wall girder and is $0,06066 \mathrm{MPa}$.

3.6. High-wall girder 1,15 $\mathrm{m}$ wide and loaded with the force of $500 \mathrm{kN}$ without friction

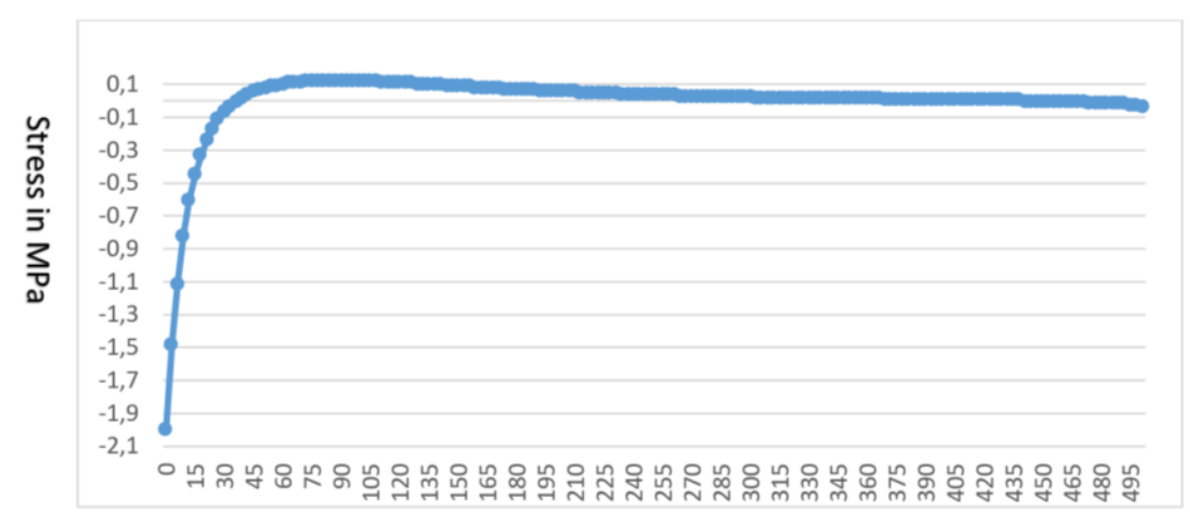

Vertically distance from the top

Fig. 8. Stress along the height of the high-wall girder

The maximum normal stress is at a distance of $87 \mathrm{~cm}$ from the top of the high-wall girder and is $0,12132 \mathrm{MPa}$.

3.7. High-wall girder 1,15 $\mathrm{m}$ wide and loaded with the force of $250 \mathrm{kN}$ with friction

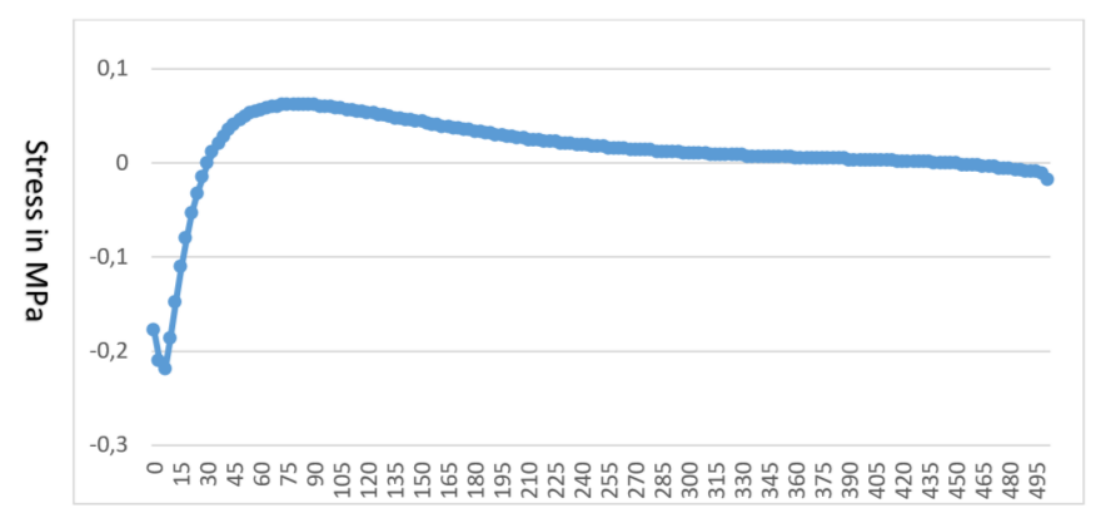

Vertically distance from the top

Fig. 9. Stress along the height of the high-wall girder

The maximum normal stress is at a distance of $81 \mathrm{~cm}$ from the top of the high-wall girder and is $0,061526 \mathrm{MPa}$. 
3.8. High-wall girder 1,15 $\mathrm{m}$ wide and loaded with the force of $500 \mathrm{kN}$ with friction

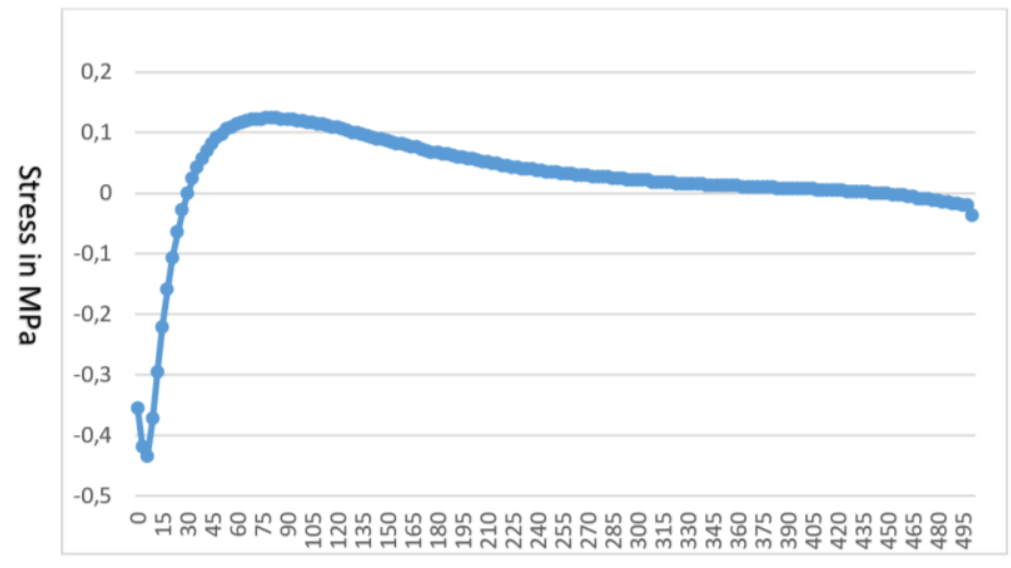

Vertically distance from the top

Fig. 10. Stress along the height of the high-wall girder

The maximum normal stress is at a distance of $81 \mathrm{~cm}$ from the top of the high-wall girder and is $0,12307 \mathrm{MPa}$.

3.9. High-wall girder 0,8 $\mathrm{m}$ wide and loaded with the force of $250 \mathrm{kN}$ without friction

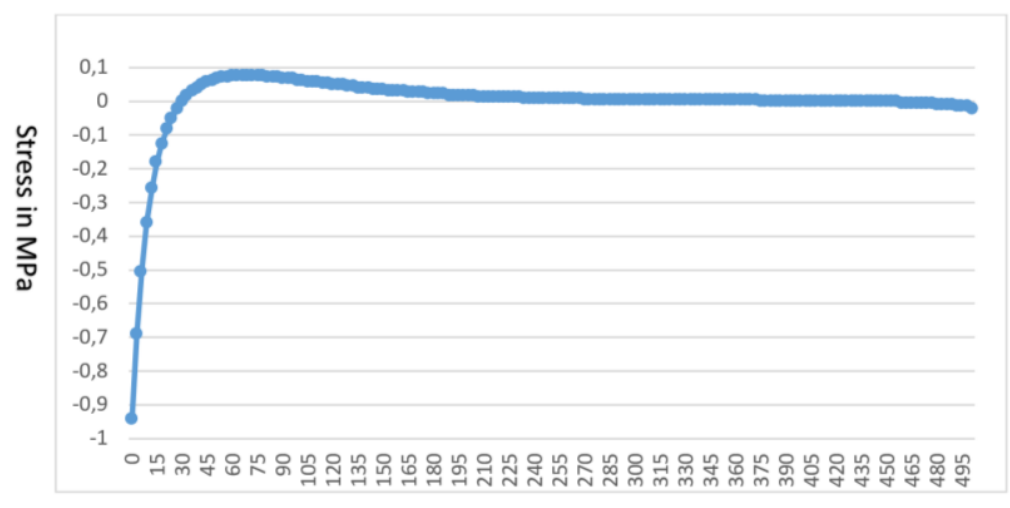

Vertically distance from the top

Fig. 11. Stress along the height of the high-wall girder

The maximum normal stress is at a distance of $69 \mathrm{~cm}$ from the top of the high-wall girder and is $0.075191 \mathrm{MPa}$.

3.10. High-wall girder 0,8 $\mathrm{m}$ wide and loaded with the force of $500 \mathrm{kN}$ without friction

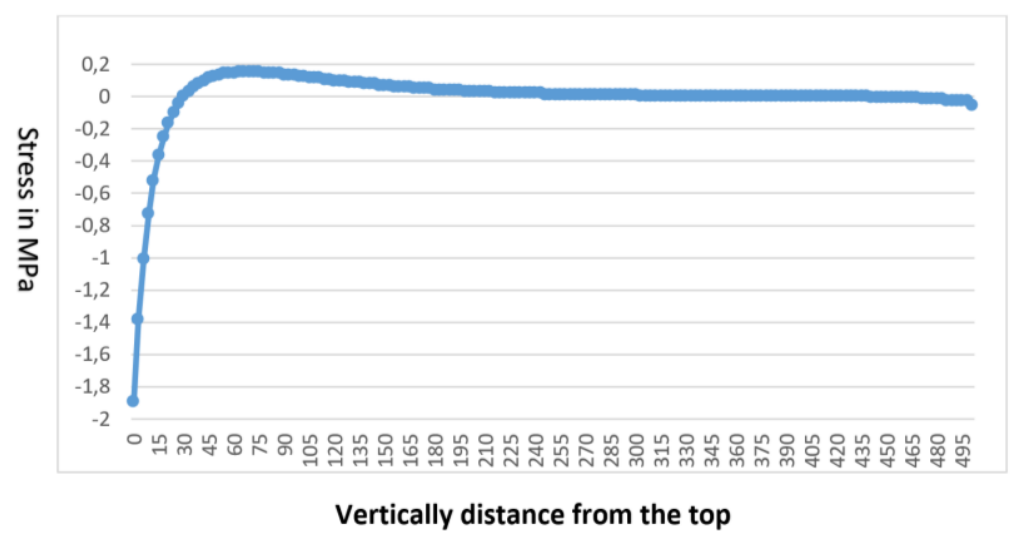

Fig. 12. Stress along the height of the high-wall girder

The maximum normal stress is at a distance of $69 \mathrm{~cm}$ from the top of the high-wall girder and is $0,15038 \mathrm{MPa}$. 


\subsection{High-wall girder 0,8 $\mathrm{m}$ wide and loaded with the force of $250 \mathrm{kN}$ with friction}

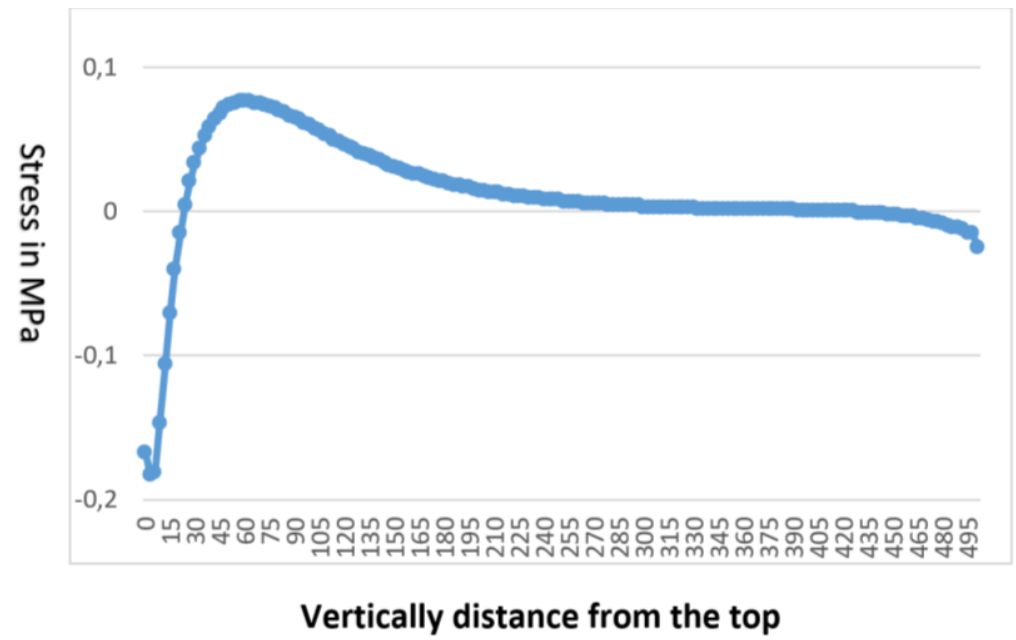

Fig. 13. Stress along the height of the high-wall girder

The maximum normal stress is at a distance of $60 \mathrm{~cm}$ from the top of the high-wall girder and is 0,076125 MPa.

\subsection{High-wall girder 0,8 $\mathrm{m}$ wide and loaded with the force of $500 \mathrm{kN}$ with friction}

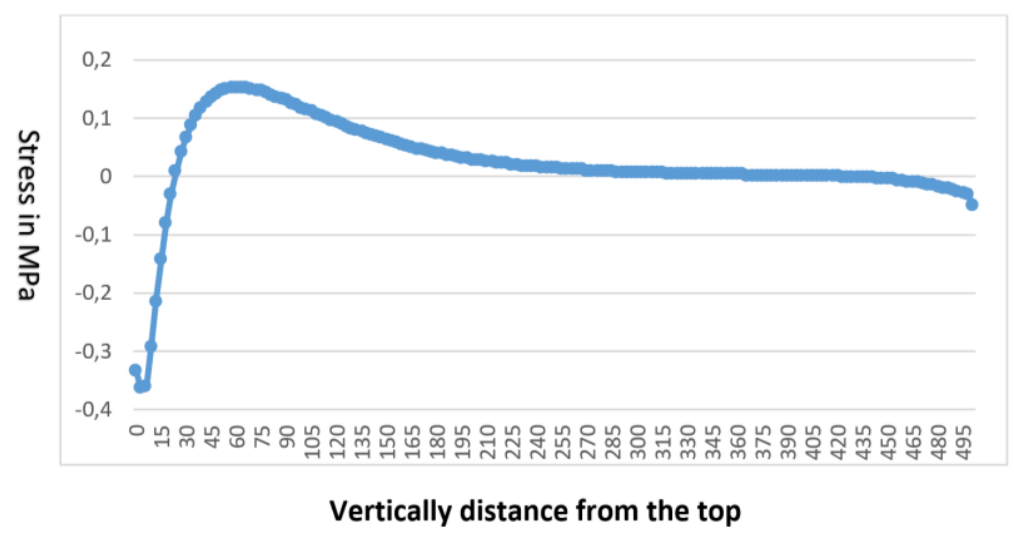

Fig. 14. Stress along the height of the high-wall girder

The maximum normal stress is at a distance of $60 \mathrm{~cm}$ from the top of the high-wall girder and is $0,15227 \mathrm{MPa}$.

\section{Interpretation of results}

It can be seen from the results that in the case of loading a wooden high-wall girder over a steel plate, the longitudinal stress along the length of the high-wall girder is higher in the case of friction between the steel plate and the high-wall girder than when the connection is frictionless. It has been shown that the maximum normal stress is at a greater distance from the top of the high-rise girder in the case of load if the connection between the steel plate and the high-wall girder is frictionless than if the connection is with friction. Also from the results it can be seen that the greater the width of the high-wall girder the maximum stress is at a greater distance from the top.

\section{Conclusion}

In the case of loading a wooden high-wall girder over a steel plate, it is shown that there is not much difference if there is friction at the contact between the high-wall girder and the steel plate and in the absence of friction, although the stress is slightly higher if there is friction. It can be seen from the results that in all cases the maximum normal stress is at a distance of approximately one tenth to one fifth of the total height of the high-wall girder seen from the top. The results showed that there would be no breakage or dangerous deformation of the wooden high-wall girder. The stresses of the wooden high-wall girders are in line with expectations. The research in this paper will lead to further tests in which the load of the wooden high-wall girder will be observed via a steel plate that will be bolted to the wooden high-wall girder, the case is higher than the maximum normal stress. 


\section{References}

[1] Ansys 2019 R3. (2019). South of Pittsburgh in Canonsburg, Pittsburgh, Pennsylvania, United States of America

[2] Ćubela, D. (2020). Wooden high-wall girders, Lecture from Basics of wooden structures, Faculty of civil engineering, University of Mostar, Mostar, Bosnia and Herzegovina

[3] Takač, S., Varevac, D., Markulak, D., Analysis of the Stress Distribution in the Semispace of the Steel Pinned Joint, The University of J. J. Strossmayer in Osijek, Civil Engineering Faculty, Osijek, Croatia

[4] https://www.grad.unizg.hr/_download/repository/Svojstva_drva_2014\%5B2\%5D.pdf, 2014, Faculty of civil engineering, University of Zagreb, Accessed on: 2009-09-27

[5] https://drvene-konstrukcije.hr/wp-content/uploads/2010/02/14.pdf, 2010, Accessed on: 2009-09-28

[6] Newaz, G., Mayeed, M., Rasul, A. (2016). Characterization of balsa wood mechanical properties required for continuum damage mechanics analysis, Journal of Materials: Design and Applications, Vol. 230, No. 1, 2016, pp. 206-218, DOI: $10.1177 / 1464420714564711$

[7] Brauns, J., Rocens, K., Lawal, S. A. (2018). Modification of Wood: Mechanical Properties and Application, Reference Module in Materials Science and Materials Engineering, DOI: 10.1016/B978-0-12-803581-8.11226-3

[8] https://en.wikipedia.org/wiki/Wood, Wood, Wikipedia, the free encyclopedia, Accessed on: 2009-09-28 